Check for updates

Cite this: Mater. Adv., 2021,

2, 1657

Received 19th October 2020

Accepted 10th January 2021

DOI: $10.1039 / \mathrm{d} 0 \mathrm{ma} 00816 \mathrm{~h}$

rsc.li/materials-advances

\title{
Mechanical, thermal, and microstructural analyses of thermoplastic poly(2-methoxyethyl acrylate)- based polyurethane by RAFT and polyaddition $\dagger$
}

\author{
Shunsuke Tazawa, ${ }^{a}$ Tomoki Maeda (D) *ab and Atsushi Hotta (D) *a
}

\begin{abstract}
Mechanical and thermal properties of the newly synthesized solid poly(2-methoxyethyl acrylate) (PMEA)based polyurethane (PU) were studied. The obtained PMEA-based PUs with various molecular weights were thermoplastic, synthesized by reversible addition-fragmentation chain transfer (RAFT) and polyaddition. Dynamic mechanical analysis (DMA) revealed that the storage modulus and the melting temperature of PMEA-based PU significantly increased from $1.5 \times 10^{4} \mathrm{~Pa}$ to $2.3 \times 10^{5} \mathrm{~Pa}$ and from $25{ }^{\circ} \mathrm{C}$ to $73{ }^{\circ} \mathrm{C}$, respectively, as the molecular weight of PMEA-based PU increased. This enhancement in the properties could be due to the formation of an ordered structure in PMEA-based PU, studied using small-angle and wide angle X-ray scattering (SAXS, WAXS). Glass transition temperature, 5\% weightreduction temperature, and the amount of intermediate water of PMEA-based PU were also analyzed using differential scanning calorimetry (DSC) and thermogravimetric analysis (TGA).
\end{abstract}

\section{Introduction}

Poly (2-methoxyethyl acrylate) (PMEA) is frequently used in biomedical coating due to its liquid-like properties. PMEA possessed excellent properties for medical applications, such as cell enrichment, ${ }^{1-4}$ low protein absorption, ${ }^{5}$ and antithrombogenicity. ${ }^{6,7}$ Among the properties, antithrombogenicity is particularly important for the devices that are in direct contact with blood. ${ }^{8-15}$ The glass transition temperature $\left(T_{\mathrm{g}}\right)$ of PMEA is found to be around $-30{ }^{\circ} \mathrm{C}$. Therefore, PMEA has been used for coating artificial organs, ${ }^{5,16,17}$ but it was found to be rather unstable in vivo, because PMEA turns to a viscous liquid at body temperature.

To further extend its biomedical applications, various attempts to obtain solid PMEA at physiological temperature have been made for stable and long-lasting coating. Hirata et al. reported its blending with other polymers possessing a higher glass transition temperature $\left(T_{\mathrm{g}}\right)$. In their report, a solid PMEAbased material was obtained by mixing poly (methyl methacrylate) (PMMA) with a $T_{\mathrm{g}}$ of $\sim 110{ }^{\circ} \mathrm{C}$ into PMEA. The polymer blend could eventually achieve an antithrombogenic surface. ${ }^{18}$ Jankova et al. reported copolymerization with other polymers possessing

\footnotetext{
${ }^{a}$ Department of Mechanical Engineering, Keio University 3-14-1 Hiyoshi, Kohoku-ku, Yokohama 223-8522, Japan. E-mail: hotta@mech.keio.ac.jp ${ }^{b}$ Frontier Research Center for Applied Atomic Sciences,

Ibaraki University 162-1 Shirakata, Tokai-mura, Naka-gun, Ibaraki 319-1106, Japan. E-mail: tomoki.maeda.polymer@vc.ibaraki.ac.jp

$\dagger$ Electronic supplementary information (ESI) available. See DOI: 10.1039/ d0ma00816h
}

higher $T_{\mathrm{g}}$. In their report, solid PMEA was synthesized by copolymerizing MEA and 2-[3-(6-methyl-4-oxo-1,4-dihydropyrimidin-2yl)ureido]ethyl methacrylate. ${ }^{19}$

Introducing hydrogen bonding into polymeric structures is known to be an efficient way to solidify materials. Polymers with hydrogen-bonding units can be solidified through intermolecular hydrogen bonding, which would make them thermoplastic, as hydrogen bonding is a type of reversible molecular bonding. Previously, we also reported a new type of thermoplastic solid polydimethylsiloxane (PDMS) by introducing L-phenylalanine-based hydrogen-bonding networks. ${ }^{20}$ In addition to the thermoplastic properties, self-healing properties could also be added to polymers by hydrogen bonding. For example, a self-healing supramolecular complex was reported by Cordier et $a{ }^{21} \mathrm{~A}$ new self-healing copolymer synthesized by grafting amide-containing polyacrylate brushes on polystyrene backbones was also reported by Chen et $a l^{22} \mathrm{~A}$ thermoplastic block copolymer containing hydrogen bonding based on $N$-acryloyl-Lphenylalanine and methyl acrylate was reported by Hendrich et al. ${ }^{23}$

Our group has been involved in the synthesis of thermoplastic polymers, including PMEA-based polyurethane (PU) by introducing hydrogen bonding via hydroxyl-terminated reversible addition-fragmentation chain transfer (RAFT) reagents and diisocyanate (Scheme 1). ${ }^{24,25}$ The new thermoplastic PMEA-based PU was found to be highly antithrombogenic. In this study, the mechanical and the thermal properties of PMEA-based PU were investigated by changing the molecular weight of PMEA-based PU. In more detail, the molecular weight of PMEA-based PU was 

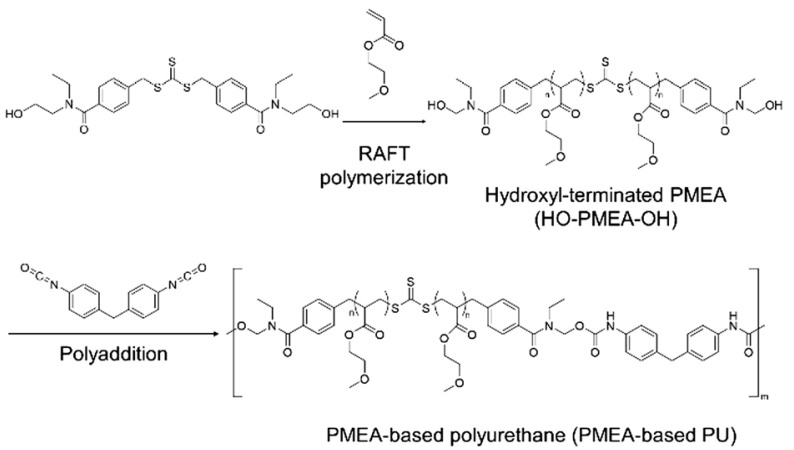

Scheme 1 Synthetic procedure of PMEA-based PU.

controlled by the ratio of diisocyanate to PMEA with hydroxyl groups in both its ends (HO-PMEA-OH) synthesized by RAFT. Thermomechanical properties were analyzed by dynamic mechanical analysis (DMA). Structural analyses by small-angle and wide-angle X-ray scattering (SAXS and WAXS) were also conducted to study the enhancement of its mechanical properties. For the analysis of the thermal properties including thermal stability, the synthesized PMEA-based PU was analyzed using differential scanning calorimetry (DSC) and thermogravimetric analysis (TGA). Finally, to discuss the excellent antithrombogenicity of PMEA-based PU, the intermediated water, which was effectively interacting with PMEA, was investigated using DSC.

\section{Experimental}

\subsection{Materials}

2-Methoxyethyl acrylate (MEA) (Tokyo Chemical Industry, Tokyo, Japan) as a monomer, 2,2'-azobis[2-methyl- $N$-(2-hydroxyethyl) propionamide] (Wako Pure Chemical Industry, Tokyo, Japan) as an initiator, bis[4-[ethyl-(2-hydroxyethyl)carbamoyl] benzyl] trithiocarbonate (Wako Pure Chemical Industry, Tokyo, Japan) as a RAFT agent, and $N, N$-dimethylformamide (DMF, $>99.9 \%$ ) (Sigma-Aldrich, Tokyo, Japan) as a solvent were purchased and used for the polymerization of HO-PMEA-OH. The stabilizer in MEA was removed using an inhibitor remover (Sigma-Aldrich, Tokyo, Japan).

4,4'-Methylenebis(phenyl isocyanate) (Tokyo Chemical Industry, Tokyo, Japan) as a polyaddition agent, dibutyltin dilaurate (Tokyo Chemical Industry, Tokyo, Japan) as a catalyst, and toluene (Wako Pure Chemical Industry, Tokyo, Japan), super-dehydrated toluene (Kanto Chemical Co., Inc., Tokyo, Japan), tetrahydrofuran (THF) (Wako Pure Chemical Industry, Tokyo, Japan) and diethyl ether (Wako Pure Chemical Industry, Tokyo, Japan) as solvents were purchased and used for the polymerization of PMEA-based PU.

\subsection{Polymerization of HO-PMEA-OH}

HO-PMEA-OH was synthesized by RAFT polymerization in the same manner as described in our previous paper. ${ }^{24}$ In brief, for the synthesis of HO-PMEA-OH with a molecular weight of 8000 (HO-PMEA-OH $8 \mathrm{k}$ ), $200 \mathrm{mmol}(26 \mathrm{~g}$ ) of MEA, $80 \mathrm{~mL}$ of DMF, and $4.0 \mathrm{mmol}(2.08 \mathrm{~g})$ of bis[4-[ethyl-(2-hydroxyethyl) carbamoyl] benzyl] trithiocarbonate were added into a dried reaction flask. Then, the freeze-pump-thaw cycle was repeated three times. After the removal of oxygen, $2.0 \mathrm{mmol}(0.58 \mathrm{~g})$ of $2^{\prime}$-azobis [2methyl- $N$-(2-hydroxyethyl) propionamide] was added into the flask, and the RAFT polymerization was started at $70{ }^{\circ} \mathrm{C}$ under an argon atmosphere for $24 \mathrm{~h}$. Finally, the reaction solution was precipitated in distilled water and the precipitate was dried under vacuum. In this study, in addition to HO-PMEA-OH $8 \mathrm{k}$, HO-PMEA-OH with a molecular weight of 80000 (HO-PMEA-OH $80 \mathrm{k}$ ) was also synthesized.

\subsection{Polymerization of PMEA-based polyurethane (PU)}

PMEA-based PU was synthesized by the polyaddition in the same manner as described in our previous paper. ${ }^{24}$ In brief, for the synthesis of PMEA-based PU with a molecular weight of 80000 (PMEA-based PU $80 \mathrm{k}$ ), HO-PMEA-OH $8 \mathrm{k}(3.0 \mathrm{~g}$, $0.38 \mathrm{mmol}$ ) dissolved in toluene was poured into a dried reaction flask. After the evaporation of toluene at $50{ }^{\circ} \mathrm{C}$ under vacuum to remove water in HO-PMEA-OH, HO-PMEA-OH was again dissolved in $20 \mathrm{~mL}$ of super-dehydrated toluene. Then, a $5.0 \mathrm{~mL}$ solution of $4,4^{\prime}$-methylenebis(phenyl isocyanate) $(0.19 \mathrm{~g}$, $0.76 \mathrm{mmol})$ in super-dehydrated toluene and dibutyltin dilaurate $(0.06 \mathrm{~g}, 0.10 \mathrm{mmol})$ were added into the reaction flask, and the reaction was conducted at $50{ }^{\circ} \mathrm{C}$ under an argon atmosphere for $48 \mathrm{~h}$. Finally, the reaction solution was precipitated in diethyl ether. In this study, in addition to PMEA-based PU 80 k, PMEA-based PU with a molecular weight of 50000 (PMEA-based PU $50 \mathrm{k}$ ) was also synthesized.

Furthermore, for the mechanical, thermal, and structural analyses, solid films were prepared. In detail, PMEA-based PU was dissolved in $5.0 \mathrm{~mL}$ of THF, and the solution was poured into a polytetrafluoroethylene mold, before it was dried at room temperature for $40 \mathrm{~h}$, which was followed by the drying process at room temperature under vacuum for $24 \mathrm{~h}$.

\subsection{Chemical structure analysis by NMR}

The chemical structures of HO-PMEA-OH and PMEA-based PU were analyzed by ${ }^{1} \mathrm{H}-\mathrm{NMR}$ using an ECA500 instrument (JEOL Ltd, Tokyo, Japan). DMSO-d ${ }_{6}$ was used as the solvent for HO-PMEA-OH and PMEA-based PU $50 \mathrm{k}$, and $\mathrm{CDCl}_{3}$ was used for PMEA-based PU $80 \mathrm{k}$.

HO-PMEA-OH. ${ }^{1} \mathrm{H}$ NMR (500 MHz, DMSO-d $\left.\mathrm{d}_{6}, \mathrm{ppm}\right): \delta 2.20-$ $2.35\left(\mathrm{~d} ;-\mathrm{CH}_{2} \mathrm{CH}-+\mathrm{CH}_{2}-\mathrm{Ph}\right), \delta 1.32-1.83\left(\mathrm{brm} ;-\mathrm{CH}_{2} \mathrm{CH}-\right), \delta 4.08$ $\left(\mathrm{s} ;-\mathrm{OCH}_{2} \mathrm{CH}_{2} \mathrm{OCH}_{3}\right), \delta 3.46\left(\mathrm{~s} ;-\mathrm{OCH}_{2} \mathrm{CH}_{2} \mathrm{OCH}_{3}\right), \delta 3.23$ (s; $\left.-\mathrm{OCH}_{2} \mathrm{CH}_{2} \mathrm{OCH}_{3}\right), \delta 7.18(\mathrm{~d} ; \mathrm{H}-\mathrm{Ph})$ and $7.23(\mathrm{~d} ; \mathrm{H}-\mathrm{Ph}){ }^{26}$

PMEA-based PU 50 k. ${ }^{1} \mathrm{H}$ NMR (500 MHz, DMSO- $\left.\mathrm{d}_{6}, \mathrm{ppm}\right)$ : $\delta$ 2.20-2.35 (d; - $\left.-\mathrm{CH}_{2} \mathrm{CH}-+\mathrm{CH}_{2}-\mathrm{Ph}\right), \delta 1.32-1.83$ (brm; $-\mathrm{CH}_{2} \mathrm{CH}-$ ), $\delta 4.08\left(\mathrm{~s} ;-\mathrm{OCH}_{2} \mathrm{CH}_{2} \mathrm{OCH}_{3}\right), \delta 3.46\left(\mathrm{~s} ;-\mathrm{OCH}_{2} \mathrm{CH}_{2} \mathrm{OCH}_{3}\right), \delta 3.23$ $\left(\mathrm{s} ; \quad-\mathrm{OCH}_{2} \mathrm{CH}_{2} \mathrm{OCH}_{3}\right), \quad \delta \quad 3.77 \quad\left(\mathrm{~s} ; \quad-\mathrm{Ph}-\underline{\mathrm{CH}}_{2}-\mathrm{Ph}-\right), \quad \delta \quad 9.54$ (s; -CONH-), $\delta$ 7.04-7.36 (brm; H-Ph). ${ }^{27,28}$

PMEA-based PU 80 k. ${ }^{1} \mathrm{H}$ NMR $\left(500 \mathrm{MHz}, \mathrm{CDCl}_{3}, \mathrm{ppm}\right): \delta$ 2.30-2.66 (d; - $\left.\mathrm{CH}_{2} \mathrm{C} \underline{\mathrm{H}}-+\mathrm{CH}_{2}-\mathrm{Ph}\right), \delta 1.42-2.06\left(\mathrm{brm} ;-\mathrm{CH}_{2} \mathrm{CH}-\right.$ ), $\delta 4.19\left(\mathrm{~s} ;-\mathrm{OCH}_{2} \mathrm{CH}_{2} \mathrm{OCH}_{3}\right), \delta 3.56\left(\mathrm{~s} ;-\mathrm{OCH}_{2} \mathrm{CH}_{2} \mathrm{OCH}_{3}\right)$, $\delta 3.35\left(\mathrm{~s} ;-\mathrm{OCH}_{2} \mathrm{CH}_{2} \mathrm{OCH}_{3}\right), \delta 3.89\left(\mathrm{~s} ;-\mathrm{Ph}-\mathrm{CH}_{2}-\mathrm{Ph}-\right), \delta 6.76-$ $6.90(\mathrm{~s} ;-\mathrm{CON} \underline{\mathrm{H}}-), \delta$ 6.90-7.34 (brm; H-Ph). ${ }^{29}$ 


\subsection{Molecular weight analysis by SEC}

The molecular weights of HO-PMEA-OH and PMEA-based PU were analyzed by size exclusion chromatography (SEC) using a Prominence HPLC system (Shimadzu Co. Ltd., Tokyo, Japan) with a column of Shodex GPC K804L (Showa Denko K.K., Tokyo, Japan). Chloroform was used as the eluent, and polystyrene (Showa Denko K.K., Tokyo, Japan) was used for the calibration.

\subsection{Hydrogen-bond unit analysis by FTIR}

The formation of hydrogen-bond units as crosslinking points was analyzed by Fourier transform infrared spectroscopy (FTIR) in ATR mode using an ALPHA-E instrument (Bruker Optics K.K., Kanagawa, Japan). The resolution was set at $4 \mathrm{~cm}^{-1}$, and the number of scans was set at 64 .

\subsection{Thermomechanical analysis}

The thermomechanical properties of HO-PMEA-OH and PMEAbased PU were analyzed by dynamic mechanical analysis (DMA) using an ARES-G2 instrument (TA Instruments Inc., Tokyo, Japan). A circular plate with a diameter of $8 \mathrm{~mm}$ was used, and the frequency was set at $1 \mathrm{~Hz}$. Temperature was changed from $-60{ }^{\circ} \mathrm{C}$ to $130{ }^{\circ} \mathrm{C}$, and the heating rate was set at $5{ }^{\circ} \mathrm{C} \min ^{-1}$. The state of the sample was defined as solid, when the storage modulus $G^{\prime}$ was higher than the loss modulus $G^{\prime \prime}$. The crossover point of $G^{\prime}$ and $G^{\prime \prime}$ was defined as the melting point.

\subsection{Structural analysis}

The structural analysis was conducted using a NANO-Viewer (Rigaku Co., Tokyo, Japan). SAXS and WAXS measurements were conducted by changing the sample-detector distance as $97 \mathrm{~mm}, 290 \mathrm{~mm}$, and $875 \mathrm{~mm}$. An X-ray $(\lambda=1.54 \AA)$ passing through three slits (1st slit: $0.2 \mathrm{~mm}$, 2nd slit: $0.1 \mathrm{~mm}$, and 3rd slit: $0.25 \mathrm{~mm}$ ) was used. The scattered X-ray was detected using a PILATUS $100 \mathrm{~K}$ detector and the obtained 2D profiles were circumferentially averaged to get the $1 \mathrm{D}$ profiles.

\subsection{DSC analysis}

DSC analysis was conducted using a DSC25 instrument (TA Instruments Inc., Tokyo, Japan). 10-15 mg of PMEA-based PU was used for the analysis. The hydrated PMEA-based PU sample was prepared by dipping the sample in $1 \mathrm{~mL}$ of distilled water for $24 \mathrm{~h}$ and by removing the distilled water from the surface. As for the measurement sequence, the sample was heated to $40{ }^{\circ} \mathrm{C}$, cooled from $40{ }^{\circ} \mathrm{C}$ to $-100{ }^{\circ} \mathrm{C}$, and heated again from $-100{ }^{\circ} \mathrm{C}$ to $50{ }^{\circ} \mathrm{C}$. The cooling and the heating rates were set at $5{ }^{\circ} \mathrm{C} \min ^{-1}$.

The ratio of intermediate water to all water was calculated using eqn (1).

$$
\text { Ratio of intermediate water }(\%)=\Delta H_{\text {Crystal }} / 334 \mathrm{Jg}^{-1} \times 100
$$

where $\Delta H_{\text {Crystal }}$ is the enthalpy of cold crystallization of water.

\subsection{Thermogravimetric analysis (TGA)}

The thermal stability of PMEA-based PU was analyzed by TGA using a DTG-60 instrument (Shimadzu, Tokyo, Japan). The sample $(20 \mathrm{mg})$ in a pan was heated from room temperature to $600{ }^{\circ} \mathrm{C}$ under a $\mathrm{N}_{2}$ atmosphere. The heating rate was set at $10{ }^{\circ} \mathrm{C} \mathrm{min}{ }^{-1}$, and the flow rate of $\mathrm{N}_{2}$ was set at $100 \mathrm{~mL} \mathrm{~min}{ }^{-1}$. $\alpha$-Alumina (Shimadzu, Tokyo, Japan) was used as the reference.

\section{Results and discussion}

\subsection{Chemical structures of HO-PMEA-OH and PMEA-based} PU

${ }^{1} \mathrm{H}-\mathrm{NMR}$ measurements were carried out to confirm the synthesis of HO-PMEA-OH and PMEA-based PU. Fig. 1 shows the typical NMR spectrum of HO-PMEA-OH with a molecular weight of $8000 \mathrm{~g} \mathrm{~mol}^{-1}$ (HO-PMEA-OH $8 \mathrm{k}$ ). It was confirmed that HO-PMEA-OH (the prepolymer for the synthesis of PMEAbased PU) was successfully polymerized via RAFT polymerization. Fig. 2 shows the NMR spectrum of PMEA-based PU with a molecular weight of $47000 \mathrm{~g} \mathrm{~mol}^{-1}$ (PMEA-based PU $50 \mathrm{k}$ ). After the chemical reaction of HO-PMEA-OH with diisocyanate, further peaks due to the reaction appeared in addition to the original peaks observed in the NMR spectrum of HO-PMEA-OH. Therefore, it was confirmed that PMEA-based PU was successfully polymerized via polyaddition.

HO-PMEA-OH and PMEA-based PU were synthesized by changing the molecular weights, which were analyzed through SEC measurements (the SEC curves were presented in Fig. S1, ESI $\dagger$ ), and the results are all listed in Table 1.

\subsection{Analysis of the chemical structures and hydrogen bonding in PMEA-based PU}

To investigate the chemical structures in the synthesized PMEA-based PU, FTIR analysis was conducted. Fig. 3 and 4 both present the FTIR spectra of the synthesized PMEA at different wavenumbers. As shown in Fig. 3, the peaks at $1610 \mathrm{~cm}^{-1}$ and $\sim 1630 \mathrm{~cm}^{-1}$ were observed in HO-PMEA-OH $8 \mathrm{k}$ in addition to the peaks derived from $\mathrm{C}=\mathrm{O}$ at $1728 \mathrm{~cm}^{-1}$, and $\mathrm{OCH}_{3}$ and $\mathrm{OCH}_{2}$ at $2800-3000 \mathrm{~cm}^{-1}$ of PMEA. ${ }^{30,31}$ The peak at $1610 \mathrm{~cm}^{-1}$ derives from the $\mathrm{C}=\mathrm{C}$ ring stretching of the

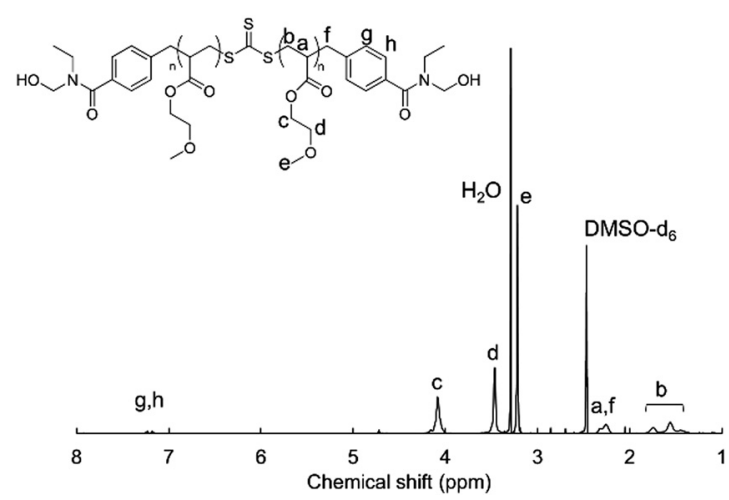

Fig. 1 NMR spectrum of HO-PMEA-OH $8 \mathrm{k}$. 

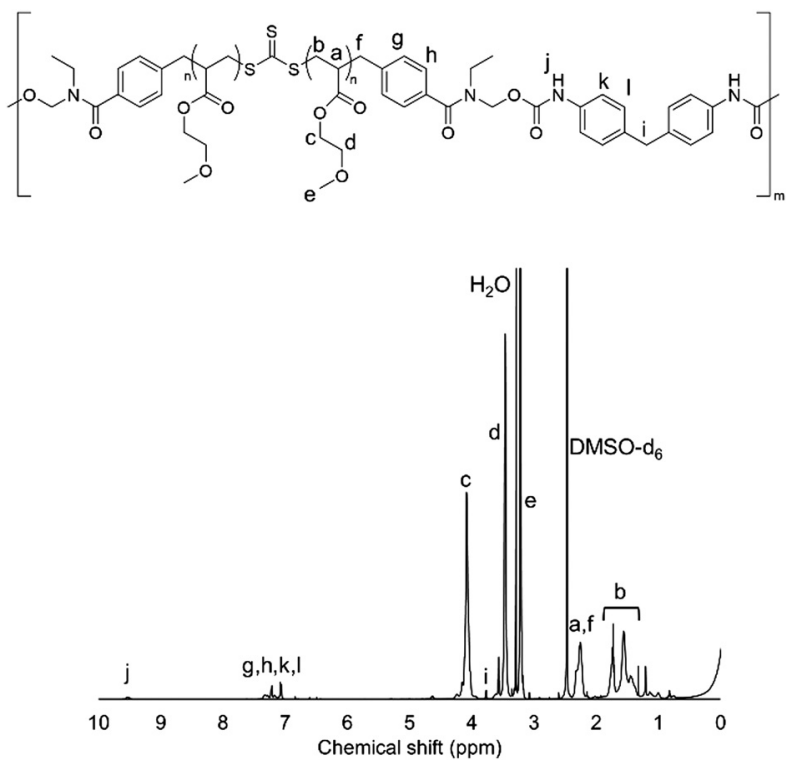

Fig. 2 NMR spectrum of PMEA-based PU $50 \mathrm{k}$.

Table 1 Molecular weights of the synthesized HO-PMEA-OH and PMEAbased PU

\begin{tabular}{lllll}
\hline Sample & $M_{\mathrm{n}}{ }^{a}$ & $M_{\mathrm{n}}{ }^{b}$ & $M_{\mathrm{w}}{ }^{b}$ & $M_{\mathrm{w}} / M_{\mathrm{n}}{ }^{b}$ \\
\hline HO-PMEA-OH 8 k & 7900 & 6100 & 7700 & 1.26 \\
HO-PMEA-OH 80 k & 82000 & 29900 & 50600 & 1.69 \\
PMEA-based PU 50 k & - & 20300 & 47100 & 2.32 \\
PMEA-based PU 80 k & - & 32100 & 82800 & 2.58
\end{tabular}

${ }^{a}$ Determined by NMR. ${ }^{b}$ Determined by SEC.

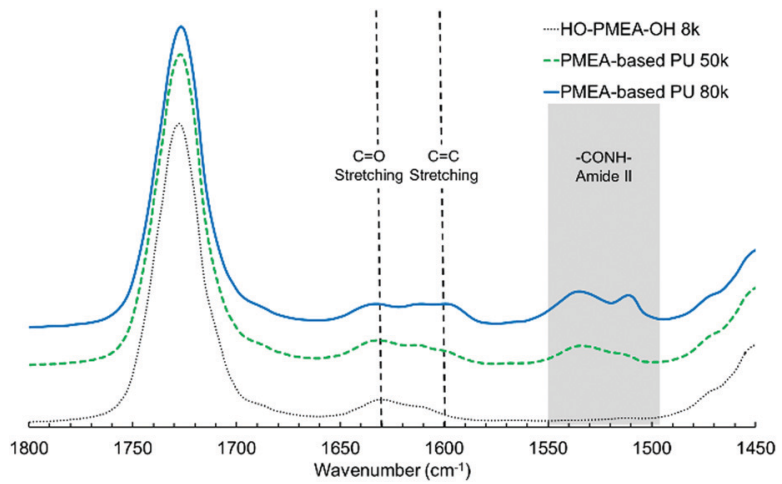

Fig. 3 FTIR spectra of PMEA-based PU $\left(1450 \mathrm{~cm}^{-1}-1800 \mathrm{~cm}^{-1}\right)$.

benzene rings of the RAFT agent, and the peak at $\sim 1630 \mathrm{~cm}^{-1}$ comes from the $\mathrm{C}=\mathrm{O}$ stretching of the amide bonds combined with the benzene rings of the RAFT agent. In a previous study, Tang et al. reported that the peak of the $\mathrm{C}=\mathrm{C}$ ring stretching in aromatic polyamide composed of trimesoyl chloride and 1,3benzenediamine was found at $1609 \mathrm{~cm}^{-1}$. ${ }^{32}$ Fukumaru et al. also reported that the peak of the $\mathrm{C}=\mathrm{O}$ stretching was at $1640 \mathrm{~cm}^{-1}$ in the tert-butyldimethylsilyl (TBS)-functionalized poly ( $p$-phenylene benzobisoxazole) (PPBO) precursor. ${ }^{33}$
In addition to the peaks observed in HO-PMEA-OH $8 \mathrm{k}$, the peaks at $1535 \mathrm{~cm}^{-1}$ and $1599 \mathrm{~cm}^{-1}$ were newly detected after the polyaddition of HO-PMEA-OH, which could only be observed for PMEA-based PU (i.e. PMEA-based PU of $80 \mathrm{k}$ and $50 \mathrm{k}$ ). The peaks between $1500 \mathrm{~cm}^{-1}$ and $1560 \mathrm{~cm}^{-1}$ derive from the combination of the $\mathrm{N}-\mathrm{H}$ in plane bending and the $\mathrm{C}-\mathrm{N}$ stretching (amide II), and the peak at $1599 \mathrm{~cm}^{-1}$ derives from the $\mathrm{C}=\mathrm{C}$ ring stretching of the benzene rings of diisocyanate. In fact, $\mathrm{Xu}$ et al. previously reported that the peak of amide II could be observed between $1500 \mathrm{~cm}^{-1}$ and $1600 \mathrm{~cm}^{-1}$ in a urethane elastomer composed of polycarbonate diols, isophorone diamine, and isophorone diisocyanate. ${ }^{34}$ Xiang et al. also reported that the peaks of amide II were found between $1480 \mathrm{~cm}^{-1}$ and $1560 \mathrm{~cm}^{-1}$ in polyurethane composed of hydroxyl-terminated butadiene-acrylonitrile copolymer, hexamethylene diisocyanate, and 3,3'-dimethyl-4,4'-diamino dicyclohexyl methane. ${ }^{35}$ Moreover, Stefanovic et al. reported that the peak of the $\mathrm{C}=\mathrm{C}$ ring stretching of diisocyanate $\left(4,4^{\prime}\right.$ methylenebis(phenyl isocyanate)) was detected at $1600 \mathrm{~cm}^{-1}$ in polyurethane synthesized from hydroxyl-terminated poly (propylene oxide)- $b$-PDMS- $b$-poly(propylene oxide) using $4,4^{\prime}$ methylenebis(phenyl isocyanate). ${ }^{28}$ Therefore, it was indicated that the polyaddition using diisocyanate was successfully conducted.

The existence of hydrogen bonding was also confirmed by the FTIR spectra. It was known that the peaks originating from free $\mathrm{C}=\mathrm{O}$ and hydrogen-bonded $\mathrm{C}=\mathrm{O}$ stretching in urethane could be observed at $1719 \mathrm{~cm}^{-1}$ and $1704 \mathrm{~cm}^{-1}$, respectively. ${ }^{36}$ As presented in Fig. 3, however, the peak between $1700 \mathrm{~cm}^{-1}$ and $1750 \mathrm{~cm}^{-1}$ originating from the MEA monomers of PMEAbased PU $80 \mathrm{k}$ and PMEA-based PU $50 \mathrm{k}$ overlapped with the peak of HO-PMEA-OH $8 \mathrm{k}$. Since the molar ratio of $\mathrm{C}=\mathrm{O}$ in MEA to that of $\mathrm{C}=\mathrm{O}$ in urethane was approximately $25: 1$, a significantly large $\mathrm{C}=\mathrm{O}$ peak of the MEA could easily involve the urethane-derived $\mathrm{C}=\mathrm{O}$ peak. As shown in Fig. 4, the broad peak centered at $\sim 3340 \mathrm{~cm}^{-1}$ derives from the hydrogenbonded $\mathrm{N}-\mathrm{H}$ stretching. Jena et al. reported that the peak of the stretching vibration of the amide bonds could be observed at $3340 \mathrm{~cm}^{-1}$ in the hyper-branched polyurethane-urea composed of glycerol, 2,2-bis(methylol)propionic acid, and isophorone diisocyanate. ${ }^{37}$ Aoki et al. also reported that the

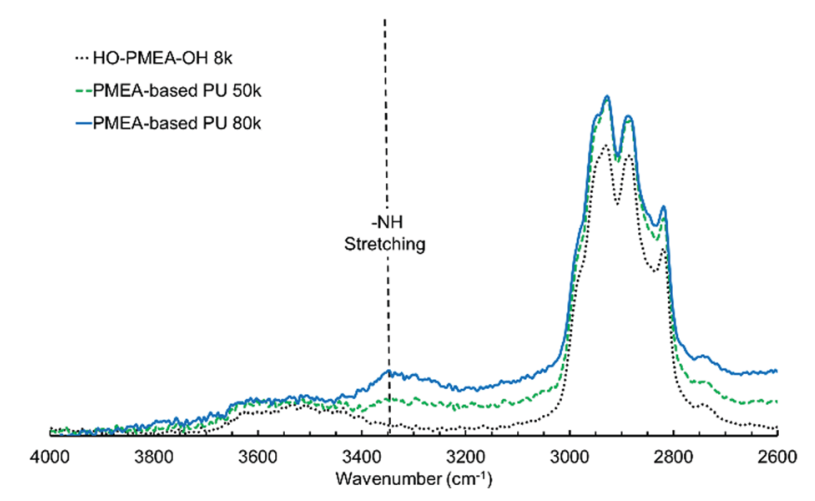

Fig. 4 FTIR spectra of PMEA-based PU $\left(2600 \mathrm{~cm}^{-1}-4000 \mathrm{~cm}^{-1}\right)$. 
peak of the stretching vibration of the amide bonds was detected at $\sim 3320 \mathrm{~cm}^{-1}$ in polyurethane composed of propanediol and diisocyanate. ${ }^{38}$ It was, therefore, considered that hydrogen bonding was successfully introduced into PMEA molecules, which should greatly contribute to the solidification of PMEA.

\subsection{Thermomechanical properties of PMEA-based PU}

DMA was carried out to investigate the thermoplasticity of the synthesized PMEA-based PU. Fig. 5 shows the DMA results of the synthesized PMEA-based PU. As shown in Fig. 5, at the lower temperature region (from $-60{ }^{\circ} \mathrm{C}$ to $\sim-30{ }^{\circ} \mathrm{C}$ ), $G^{\prime}$ of PMEA-based PU was constant. In detail, $G^{\prime}$ values of PMEAbased PU $50 \mathrm{k}$ and PMEA-based PU $80 \mathrm{k}$ were $1.9 \times 10^{6} \mathrm{~Pa}$ and $1.1 \times 10^{7} \mathrm{~Pa}$, respectively. After the glass transition temperature, $G^{\prime}$ decreased drastically. $T_{\mathrm{g}}$ values of PMEA-based $50 \mathrm{k}$ and PMEA-based PU $80 \mathrm{k}$ obtained from the $\tan \delta$ results (Fig. S2, ESI $\dagger$ ) were $-30.7{ }^{\circ} \mathrm{C}$ and $-24.8{ }^{\circ} \mathrm{C}$, respectively. At around the ambient temperature (from $0{ }^{\circ} \mathrm{C}$ to $30{ }^{\circ} \mathrm{C}$ ), the solid-state region (i.e. the region where the storage modulus $G^{\prime}$ was higher than the loss modulus $G^{\prime \prime}$ ) appeared, and accordingly, the melting point emerged by introducing hydrogen bonding. In detail, $G^{\prime}$ values of PMEA-based PU $50 \mathrm{k}$ and PMEA-based PU $80 \mathrm{k}$ were $1.5 \times 10^{4} \mathrm{~Pa}$ and $2.3 \times 10^{5} \mathrm{~Pa}$, respectively, and $G^{\prime}$ of PMEAbased PU $80 \mathrm{k}$ was higher than $G^{\prime \prime}$ around $25{ }^{\circ} \mathrm{C}$.

As a reference, the DMA results of HO-PMEA-OH are shown in Fig. S3 (ESI $\dagger$ ). HO-PMEA-OH $8 \mathrm{k}$ is the prepolymer for the synthesis of PMEA-based PU and HO-PMEA-OH $80 \mathrm{k}$ is the PMEA of the same molecular weight as PMEA-based PU $80 \mathrm{k}$ but without hydrogen bonding. In detail, as presented in Fig. S3(a) (ESI $\dagger$ ), $G^{\prime}$ of HO-PMEA-OH $8 \mathrm{k}$ was $19 \mathrm{~Pa}$, which was lower than the $G^{\prime \prime}$ at around $25^{\circ} \mathrm{C}$. As shown in Fig. S3(b) (ESI $\dagger$ ), the $G^{\prime}$ of HO-PMEA-OH $80 \mathrm{k}$ around $25{ }^{\circ} \mathrm{C}$ was found to be $2.5 \times 10^{3} \mathrm{~Pa}$, which was lower than the $G^{\prime \prime}$ around $25^{\circ} \mathrm{C}$ and was 92 times lower than that of PMEA-based PU $80 \mathrm{k}$.

In the region after the glass transition, from the results presented in Fig. 5 and Fig. S3 (ESI $\dagger$ ), PMEA-based PU $80 \mathrm{k}$ was in the solid state around $25{ }^{\circ} \mathrm{C}$, while the prepolymer of PMEAbased PU (i.e. HO-PMEA-OH $8 \mathrm{k}$ ) and the PMEA of the same molecular weight as PMEA-based PU $80 \mathrm{k}$ but without hydrogen bonding (i.e. HO-PMEA-OH $80 \mathrm{k}$ ) were in the liquid state

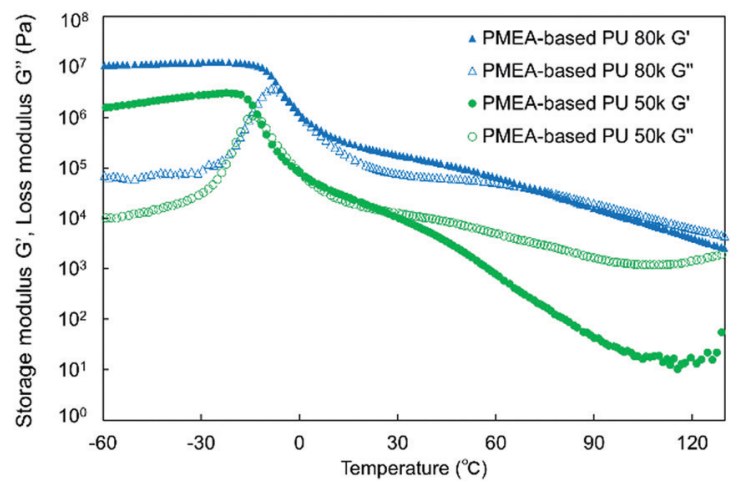

Fig. 5 DMA curves of PMEA-based PU with different molecular weights. around $25{ }^{\circ} \mathrm{C}$. Additionally, $G^{\prime}$ of PMEA-based PU increased, as the molecular weight of PMEA-based PU increased, and thus the amount of hydrogen bonding per molecular chain increased. Therefore, it was confirmed that the thermomechanical properties of PMEA-based PU was significantly improved by introducing diisocyanate-based hydrogen bonding. In previous studies, the enhancement of the mechanical properties by introducing hydrogen-bonding was reported, where the importance of the control of the amount of hydrogen bonding was carefully discussed. For example, Hayashi et al. reported that the plateau modulus of their triblock copolymer-based elastomer with acrylamide-based hydrogen bonding was $\sim 3$ times higher than that of the triblock copolymer-based elastomer without hydrogen bonding. ${ }^{39}$ In addition, Stefanovic et al. also reported that, by increasing the amount of hydrogen bonding, the storage modulus has increased from $2.3 \times 10^{8} \mathrm{~Pa}$ to $4.9 \times 10^{8} \mathrm{~Pa}$ at $25{ }^{\circ} \mathrm{C}$ for polyurethane synthesized from hydroxylterminated poly(propylene oxide)- $b$-PDMS- $b$-poly(propylene oxide) using $4,4^{\prime}$-methylenebis(phenyl isocyanate). ${ }^{28}$

The melting points of PMEA-based PU $50 \mathrm{k}$ and $80 \mathrm{k}$ were also determined to be at $25{ }^{\circ} \mathrm{C}$ and $73{ }^{\circ} \mathrm{C}$, respectively, from the crossover points of the $G^{\prime}$ and the $G^{\prime \prime}$ curves. It was, therefore, confirmed that the melting temperature was increased by increasing the amount of hydrogen bonding per molecular chain. In the previous study, Stefanovic et al. reported that the melting temperature was increased from $140{ }^{\circ} \mathrm{C}$ to $158{ }^{\circ} \mathrm{C}$ for their polyurethane synthesized from hydroxyl-terminated poly(propylene oxide)- $b$-PDMS- $b$-poly(propylene oxide) using $4,4^{\prime}$-methylenebis(phenyl isocyanate) by increasing the amount of hydrogen bonding. ${ }^{28}$

In order to discuss the enhancement of the mechanical and the thermal properties of PMEA-based PU by increasing the molecular weight, the structural analyses were performed by SAXS and WAXS. Fig. 6 shows the SAXS and WAXS profiles of PMEA-based PU. As shown in Fig. 6, $I(q)$ of PMEA-based PU $80 \mathrm{k}$ exhibited deviations from the decrease according to the power law of $\mathrm{q}^{-4}$ in the $q$ range below $0.2 \AA^{-1}$, and a sharp peak was observed at $0.51 \AA^{-1}$ in addition to the broad peaks of PMEA-based PU $80 \mathrm{k}$. In contrast, $I(q)$ of PMEA-based PU $50 \mathrm{k}$ decreased according to the power law of $q^{-4}$ below $0.03 \AA^{-1}$, and no sharp peak was observed other than the broad peaks of

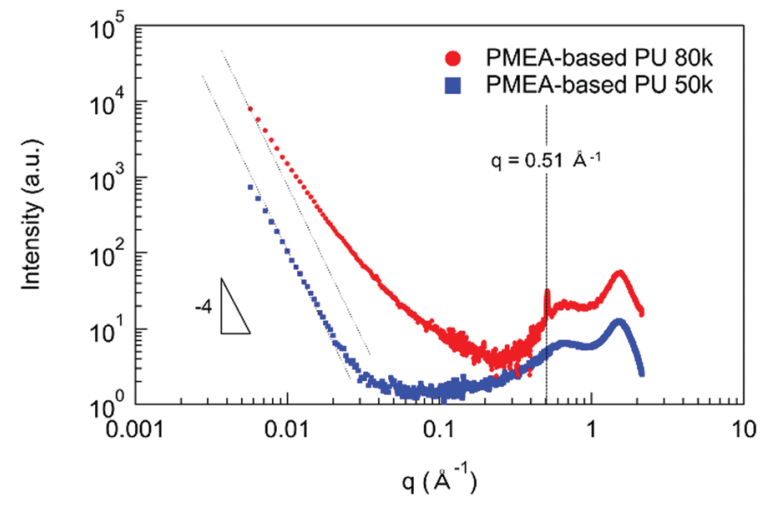

Fig. 6 SAXS and WAXS profiles of PMEA-based PU. 
PMEA-based PU $50 \mathrm{k}$. Therefore, it was confirmed that microphase-separated disorder structures with diffused phase-boundary and crystalline lattice planes $(d \sim 1.2 \mathrm{~nm})$ were formed, which was observed by WAXS and SAXS, when the molecular weight and the amount of hydrogen bonding increased. In the previous study, Bonart and Muller reported the state of segregation in the urethane elastomers evaluated by SAXS. ${ }^{40}$ Koberstein also reported the SAXS results of the microphase-separated structures with the diffused phaseboundary in the segmented polyurethane elastomers. ${ }^{41,42}$ Nozaki et al. also reported that the PU elastomers synthesized with poly(oxytetramethylene) glycol, trans-1,4-bis(isocyanatomethyl) cyclohexane, and 1,4-butanediol exhibited a microphaseseparated structure with diffused phase-boundary. ${ }^{43}$ Moreover, Xiang et al. reported that polyurethanes composed of ethylene glycol, hexamethylene diisocyanate, and hydroxyl-terminated butadiene-acrylonitrile copolymer had a crystalline structure with an interplane distance of $1.33 \mathrm{~nm} .{ }^{44}$

\subsection{Thermal properties of PMEA-based PU}

The thermal properties of PMEA-based PU were evaluated by DSC (Fig. 7). As shown in Fig. 7, the glass transition was clearly observed for all samples and the glass transition temperature $T_{\mathrm{g}}$ of PMEA-based PU was slightly higher than the $T_{\mathrm{g}}$ of HO-PMEA-OH. Moreover, $T_{\mathrm{g}}$ of PMEA-based PU was slightly increased as the molecular weight of PMEA-based PU increased. The thermal properties of the synthesized PMEA are summarized in Table 2. In detail, $T_{\mathrm{g}}$ values of PMEA-based PU $50 \mathrm{k}$ and PMEAbased PU $80 \mathrm{k}$ determined by the DSC measurements were $-35.2{ }^{\circ} \mathrm{C}$ and $-29.3{ }^{\circ} \mathrm{C}$, respectively, while those of HO-PMEA$\mathrm{OH} 8 \mathrm{k}$ and HO-PMEA-OH $80 \mathrm{k}$ were $-41.5{ }^{\circ} \mathrm{C}$ and $-38.0{ }^{\circ} \mathrm{C}$, respectively. The increase of $T_{\mathrm{g}}$ could be largely attributed to the formation of hydrogen bonding. In fact, Hayashi et al. also reported that the $T_{\mathrm{g}}$ of poly(4-vinylpyridine)- $b$-[poly(butyl acrylate)-co-polyacrylamide]- $b$-poly(4-vinylpyridine) with acrylamidebased hydrogen bonding was $22{ }^{\circ} \mathrm{C}$ higher than that of poly (4-vinylpyridine)- $b$-[poly(butyl acrylate)]- $b$-poly(4-vinylpyridine) without hydrogen bonding. ${ }^{39}$

Furthermore, thermogravimetric analysis (TGA) was conducted to investigate the thermal stability of PMEA-based PU with different molecular weights (Fig. 8). As shown in Fig. 8, the initial

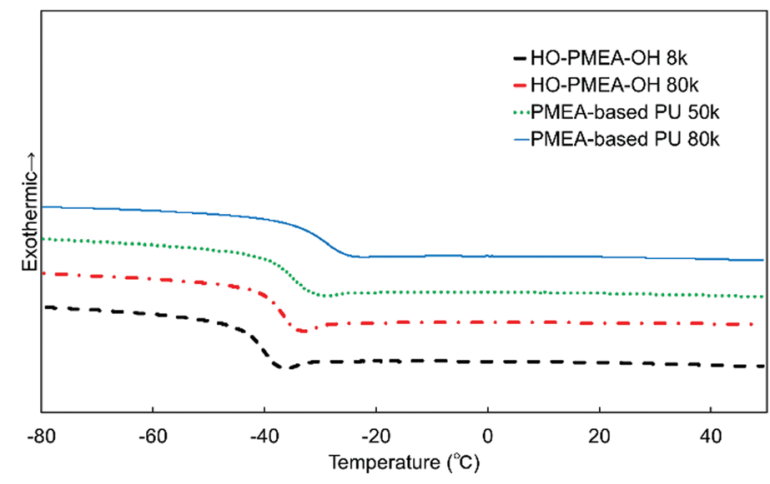

Fig. 7 DSC curves of the synthesized PMEAs.
Table 2 Thermal properties of the synthesized PMEAs

\begin{tabular}{lll}
\hline Sample & $T_{\mathrm{g}}\left[{ }^{\circ} \mathrm{C}\right]$ & $\begin{array}{l}5 \% \text { weight-reduction } \\
\text { temperature }\left[{ }^{\circ} \mathrm{C}\right]\end{array}$ \\
\hline HO-PMEA-OH $8 \mathrm{k}$ & -41.5 & 331 \\
HO-PMEA-OH $80 \mathrm{k}$ & -38.0 & 334 \\
PMEA-based PU $50 \mathrm{k}$ & -35.2 & 276 \\
PMEA-based PU 80 k & -29.3 & 278
\end{tabular}

degradation of PMEA-based PUs started at a lower temperature than HO-PMEA-OH, and then the drastic degradation happened almost at the same temperature as HO-PMEA-OH. PMEA-based PUs gradually started losing their weight from $\sim 200{ }^{\circ} \mathrm{C}$ before the drastic decrease at $\sim 350{ }^{\circ} \mathrm{C}$, while HO-PMEA-OH started losing their weight from $\sim 300{ }^{\circ} \mathrm{C}$. The initial slow degradation of PMEAbased PU around $200{ }^{\circ} \mathrm{C}$ could be due to the degradation of the urethane bond, and the drastic degradation around $350{ }^{\circ} \mathrm{C}$ after the initial degradation could result from the degradation of the main polymeric chains of PMEA. In addition, as shown in Fig. 8 and Fig. S4 (ESI $\dagger$ ), both PMEA-based PU and HO-PMEA-OH with different molecular weights also exhibited similar TGA curves, respectively, indicating that the molecular weight did not largely affect the thermal stability of the synthesized PMEA. In detail, 5\% weight-reduction temperatures of PMEA-based PU $50 \mathrm{k}$ and $80 \mathrm{k}$ were $276{ }^{\circ} \mathrm{C}$ and $278{ }^{\circ} \mathrm{C}$, respectively, while those of HO-PMEA-OH $8 \mathrm{k}$ and $80 \mathrm{k}$ were $331{ }^{\circ} \mathrm{C}$ and $334{ }^{\circ} \mathrm{C}$, respectively (Table 2).

According to previous papers on the degradation of urethane bonds, the bond was found to start degrading around $200{ }^{\circ} \mathrm{C} .{ }^{45,46}$ For example, Gaina et al. reported that the synthesized polyurethane composed of 2-[N,N-bis(2-methyl-2hydroxyethyl)amino]furfuryl, poly(tetramethylene ether) glycol and 4,4'-dibenzyldiisocyanate degraded from $200{ }^{\circ} \mathrm{C}$ due to the breakup of the urethane linkage. ${ }^{46}$ In contrast, according to previous papers on the degradation of PMEA, PMEA was found to degrade between $\sim 300{ }^{\circ} \mathrm{C}$ and $\sim 450{ }^{\circ} \mathrm{C}$, a much higher temperature than the urethane bond. For example, Jankova et al. reported that PMEA synthesized by free radical polymerization drastically degraded between $\sim 300{ }^{\circ} \mathrm{C}$ and $\sim 450{ }^{\circ} \mathrm{C} .{ }^{19}$

\subsection{Intermediate water in PMEA-based PU}

In this work, the intermediate water in PMEA-based PU was analyzed by DSC (Fig. 9). The intermediate water is known to be

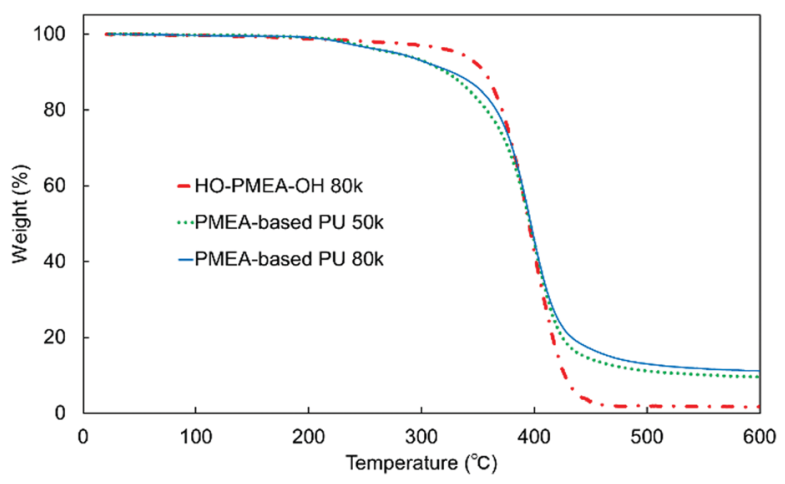

Fig. 8 TGA curves of the synthesized PMEAs. 


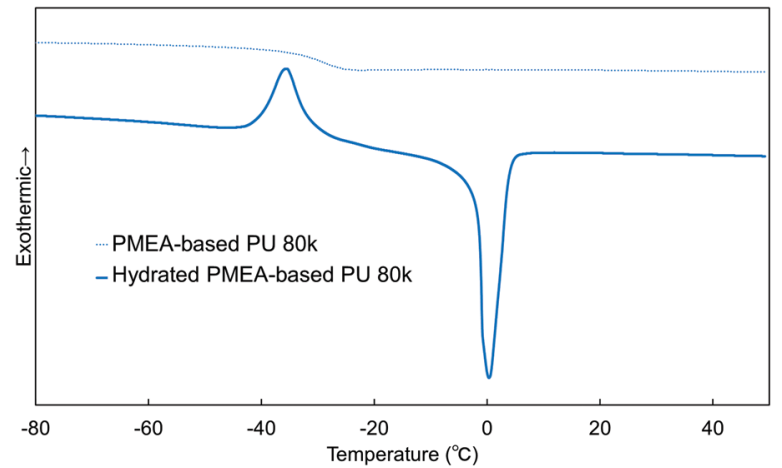

Fig. 9 DSC curves of the unhydrated and hydrated PMEA-based PUs.

composed of water molecules strongly interacting with polymers (PMEA molecular chains). It is known that the intermediate water contributes largely to the enhancement of the blood compatibility of PMEA. ${ }^{47}$ Fig. 9 shows the DSC curves measured for unhydrated and hydrated PMEA-based PU. The hydrated PMEA-based PU showed the crystallization peak of intermediate water at $-35{ }^{\circ} \mathrm{C}$ and the melting peak of water at $\sim 0{ }^{\circ} \mathrm{C}$ through the DSC measurements, while the original PMEA-based PU (i.e. the unhydrated PMEA-based PU) showed only $T_{\mathrm{g}}$ at $-29^{\circ} \mathrm{C}$. In general, such crystallization peak and the melting peak should derive from the crystallization of intermediate water and the melting of frozen water, respectively. ${ }^{48}$ Actually, in the previous study, it was reported that PMEA and PMEA-based copolymers exhibited the peak of the cold crystallization at $\sim-40{ }^{\circ} \mathrm{C}$ in DSC curves. $^{49}$

In addition, the weight ratio of intermediate water to all absorbed water was calculated from the enthalpy of cold crystallization. The ratio of intermediate water in PMEA-based PU $80 \mathrm{k}$ was found to be $3.6 \pm 0.4 \mathrm{wt} \%$, high enough to show excellent antithrombogenicity. In the previous study, Kobayashi et al. reported that the threshold of the ratio of the intermediate water for high antithrombogenicity was $1.0 \mathrm{wt} \%$ in $\operatorname{poly}(\omega-$ methoxyalkyl acrylate)s. ${ }^{48}$ Therefore, it was concluded that the intermediate water was effectively formed in PMEA-based PU even after introducing hydrogen bonding.

\section{Conclusions}

Mechanical and thermal properties of thermoplastic PMEA-based PU synthesized by RAFT polymerization using hydroxyl-terminated RAFT reagents and polyaddition using diisocyanate were investigated by changing the molecular weight of PMEA-based PU. It was found from DMA analyses that PMEA-based PU $50 \mathrm{k}$ and PMEAbased PU $80 \mathrm{k}$ were in the solid state below $25{ }^{\circ} \mathrm{C}$ and $73{ }^{\circ} \mathrm{C}$, respectively, while hydroxyl-terminated PMEA (HO-PMEA-OH $80 \mathrm{k}$ ) was in the liquid state after the glass transition region. In contrast, below the glass transition temperature, all PMEAs were in the solid state, where $T_{\mathrm{g}}$ values were detected from $-20^{\circ} \mathrm{C}$ to $-45^{\circ} \mathrm{C}$ by DMA and DSC. In addition, the storage modulus $G^{\prime}$ was also increased from $1.5 \times 10^{4} \mathrm{~Pa}$ to $2.3 \times 10^{5} \mathrm{~Pa}$ by increasing the molecular weight of PMEA-based PU from $50 \mathrm{k}$ to $80 \mathrm{k}$. The enhancement of the mechanical and thermal properties could be due to the formation of microphase-separated disorder structures with the diffused phase-boundary in PMEA-based PU, revealed by smallangle and wide-angle X-ray scattering (SAXS and WAXS). Furthermore, the $T_{\mathrm{g}}$ of PMEA-based PU was also increased from $-35.2{ }^{\circ} \mathrm{C}$ to $-29.3{ }^{\circ} \mathrm{C}$ with the increase in molecular weight, whereas the thermal stability of PMEA-based PU was not much affected by the increase in the molecular weight. Finally, PMEA-based PU was found to possess a sufficient amount of intermediate water compared to the conventional antithrombogenic materials.

\section{Conflicts of interest}

The authors declare no conflict of interest.

\section{Acknowledgements}

This work was supported in part by Grant-in-Aid for Scientific Research (A) (No. 19H00831 to A. H.), in part by Grant-in-Aid for Challenging Exploratory Research (No. 19K22067 to A. H.), in part by Grant-in-Aid for Scientific Research (B) (No. 20H02023 to T. M.), and in part by Grant-in-Aid for JSPS Fellows (No. $19 J 12154$ to S. T.) from the Japan Society for the Promotion of Science (JSPS: "KAKENHI").

\section{Notes and references}

1 T. Hoshiba, E. Nemoto, K. Sato, T. Orui, T. Otaki, A. Yoshihiro and M. Tanaka, PLoS One, 2015, e0136066.

2 M. Miyazaki, T. Maeda, K. Hirashima, N. Kurokawa, K. Nagahama and A. Hotta, Polymer, 2017, 115, 246-254.

3 Y. Okayama, K. Nakahara, X. Arouette, T. Ninomiya, Y. Matsumoto, Y. Orimo, A. Hotta, M. Omiya and N. Miki, J. Micromech. Microeng., 2010, 095018.

4 Y. Oishi, M. Nakaya, E. Matsui and A. Hotta, Composites, Part A, 2015, 73, 72-79.

5 A. Melle, A. Balaceanu, M. Kather, Y. Wu, E. Gau, W. Sun, X. Huang, X. Shi, M. Karperien and A. Pich, J. Mater. Chem. B, 2016, 4, 5127-5137.

6 C. Sato, M. Aoki and M. Tanaka, Colloids Surf., B, 2016, 145, 586-596.

7 K. Akamatsu, T. Furue, F. Han and S. Nakao, Sep. Purif. Technol., 2013, 102, 157-162.

8 T. Maeda, K. Hagiwara, S. Yoshida, T. Hasebe and A. Hotta, J. Appl. Polym. Sci., 2014, 131, 40606.

9 K. Bito, T. Hasebe, S. Maegawa, T. Maeda, T. Matsumoto, T. Suzuki and A. Hotta, J. Biomed. Mater. Res., Part A, 2017, 105, 3384-3391.

10 C. Xu, A. E. Kuriakose, D. Truong, P. Punnakitikashem, K. T. Nguyen and Y. Hong, J. Mater. Chem. B, 2018, 6, 7288-7297.

11 X. Liu, L. Yuan, D. Li, Z. Tang, Y. Wang, G. Chen, H. Chen and J. L. Brash, J. Mater. Chem. B, 2014, 2, 5718-5738. 
12 K. Enomoto, T. Hasebe, R. Asakawa, A. Kamijo, Y. Yoshimoto, T. Suzuki, K. Takahashi and A. Hotta, Diamond Relat. Mater., 2010, 19, 806-813.

13 T. Hoshida, D. Tsubone, K. Takada, H. Kodama, T. Hasebe, A. Kamijo, T. Suzuki and A. Hotta, Surf. Coat. Technol., 2007, 202, 1089-1093.

14 H. Ezura, K. Ichijo, H. Hasegawa, K. Yamamoto, A. Hotta and T. Suzuki, Vacuum, 2008, 82, 476-481.

15 H. Kodama, A. Shirakura, A. Hotta and T. Suzuki, Surf. Coat. Technol., 2006, 201, 913-917.

16 K. Sato, S. Kobayashi, M. Kusakari, S. Watahiki, M. Oikawa, T. Hoshiba and M. Tanaka, Macromol. Biosci., 2015, 15, 1296-1303.

17 T. Hirata, H. Matsuno, M. Tanaka and K. Tanaka, Phys. Chem. Chem. Phys., 2011, 13, 4928-4934.

18 T. Hirata, H. Matsuno, D. Kawaguchi, N. L. Yamada, M. Tanaka and K. Tanaka, Phys. Chem. Chem. Phys., 2015, 17, 17399-17405.

19 K. Jankova, I. Javakhishvili, S. Kobayashi, R. Koguchi, D. Murakami, T. Sonoda and M. Tanaka, ACS Appl. Bio Mater., 2019, 2, 4154-4161.

20 S. Tazawa, A. Shimojima, T. Maeda and A. Hotta, J. Appl. Polym. Sci., 2018, 135, 45419.

21 P. Cordier, F. Tournilhac, C. Soulie-Ziakovic and L. Leibler, Nature, 2008, 451, 977-980.

22 Y. L. Chen, A. M. Kushner, G. A. Williams and Z. B. Guan, Nat. Chem., 2012, 4, 467-472.

23 M. Hendrich, L. Lewerdomski and P. Vana, J. Polym. Sci., Part A: Polym. Chem., 2015, 53, 2809-2819.

24 S. Tazawa, T. Maeda, M. Nakayama and A. Hotta, Macromol. Rapid Commun., 2020, 2000346.

25 R. C. Coffin, S. J. Diamanti, A. Hotta, V. Khanna, E. J. Kramer, G. H. Fredrickson and G. C. Bazan, Chem. Commun., 2007, 3550-3552, DOI: 10.1039/b705808j.

26 A. Sudo, T. Hamaguchi, N. Aoyagi and T. Endo, J. Polym. Sci., Part A: Polym. Chem., 2013, 51, 318-326.

27 C. G. Gong and H. W. Gibson, J. Am. Chem. Soc., 1997, 119, 8585-8591.

28 I. S. Stefanovic, M. Spirkova, R. Poreba, M. Steinhart, S. Ostojic, V. Tesevic and M. V. Pergal, Ind. Eng. Chem. Res., 2016, 55, 3960-3973.

29 X. Liu, B. Yang, Z. Hou, N. Zhang and Y. Gao, Mater. Sci. Eng., C, 2019, 104, 109952.
30 S. Ye, S. Morita, G. Li, H. Noda, M. Tanaka, K. Uosaki and M. Osawa, Macromolecules, 2003, 36, 5694-5703.

31 S. Morita, M. Tanaka and Y. Ozaki, Langmuir, 2007, 23, 3750-3761.

32 C. Y. Y. Tang, Y. N. Kwon and J. O. Leckie, Desalination, 2009, 242, 149-167.

33 T. Fukumaru, T. Fujigaya and N. Nakashima, Macromolecules, 2012, 45, 4247-4253.

34 Z. Xu, X. Wang and H. Huang, J. Appl. Polym. Sci., 2020, 49575.

35 D. Xiang, M. Liu, G. Chen, T. Zhang, L. Liu and Y. Liang, RSC Adv., 2017, 7, 55610-55619.

36 K. Kojio, T. Fukumaru and M. Furukawa, Macromolecules, 2004, 37, 3287-3291.

37 K. K. Jena, D. K. Chattopadhyay and K. Raju, Eur. Polym. J., 2007, 43, 1825-1837.

38 D. Aoki and H. Ajiro, Macromolecules, 2017, 50, 6529-6538.

39 M. Hayashi, S. Matsushima, A. Noro and Y. Matsushita, Macromolecules, 2015, 48, 421-431.

40 R. Bonart and E. H. Muller, J. Macromol. Sci., Part B: Phys., 1974, 10, 345-357.

41 J. T. Koberstein and R. S. Stein, J. Macromol. Sci., Part B: Phys., 1983, 21, 1439-1472.

42 J. T. Koberstein and R. S. Stein, J. Macromol. Sci., Part B: Phys., 1983, 21, 2181-2200.

43 S. Nozaki, S. Masuda, K. Kamitani, K. Kojio, A. Takahara, G. Kuwarnura, D. Hasegawa, K. Moorthi, K. Mita and S. Yamasaki, Macromolecules, 2017, 50, 1008-1015.

44 D. Xiang, J. He, T. Cui, L. Liu, Q. S. Shi, L. C. Ma and Y. Liang, Macromolecules, 2018, 51, 6369-6379.

45 C. Carré, L. Bonnet and L. Avérous, RSC Adv., 2014, 4, 54018-54025.

46 C. Gaina, O. Ursache, V. Gaina and C. D. Varganici, eXPRESS Polym. Lett., 2013, 7, 636-650.

47 D. Murakami, N. Mawatari, T. Sonoda, A. Kashiwazaki and M. Tanaka, Langmuir, 2019, 35, 2808-2813.

48 S. Kobayashi, M. Wakui, Y. Iwata and M. Tanaka, Biomacromolecules, 2017, 18, 4214-4223.

49 R. Koguchi, K. Jankova, N. Tanabe, Y. Amino, Y. Hayasaka, D. Kobayashi, T. Miyajima, K. Yamamoto and M. Tanaka, Biomacromolecules, 2019, 20, 2265-2275. 